\title{
Effects of Dietary Supplementation with Clostridium butyricum on Growth Performance, Serum Immunity, Intestinal Morphology, and Microbiota as an Antibiotic Alternative in Weaned Piglets
}

\author{
Yunsheng Han ${ }^{1,2,3}$, Chaohua Tang ${ }^{1,2}$, Ying Li ${ }^{1,2}$, Yanan Yu ${ }^{1,2}$, Tengfei Zhan ${ }^{1,2}$, \\ Qingyu Zhao ${ }^{1,2, *}$ and Junmin Zhang ${ }^{1,2,3, *}$ \\ 1 State Key Laboratory of Animal Nutrition, Institute of Animal Sciences of Chinese Academy of Agricultural \\ Sciences, No. 2 Yuan Ming Yuan West Road, Beijing 100193, China; hanysh17@lzu.edu.cn (Y.H.); \\ jxtangchaohua@sina.com (C.T.); liying@cahg.com.cn (Y.L.); yuyananBNU@163.com (Y.Y.); \\ zhantf2019@sina.com (T.Z.) \\ 2 Scientific Observing and Experiment Station of Animal Genetic Resources and Nutrition in North China of \\ Ministry of Agriculture and Rural Affairs, Institute of Animal Science of Chinese Academy of Agricultural \\ Sciences, Beijing 100193, China \\ 3 State Key Laboratory of Grassland Agro-Ecosystems, Key Laboratory of Grassland Livestock Industry \\ Innovation, Ministry of Agriculture and Rural Affairs, College of Pastoral Agriculture Science and \\ Technology, Lanzhou University, No. 222 Tian Shui Road, Lanzhou 730020, China \\ * Correspondence: zhaoqingyu@caas.cn (Q.Z.); zhangjunmin@caas.cn (J.Z.); Tel.: +86-10-6281-5537 (Q.Z.)
}

Received: 18 November 2020; Accepted: 1 December 2020; Published: 3 December 2020

Simple Summary: Many countries have banned the use of antibiotic growth promoters (AGPs), which negatively affect weanling piglets' growth performance and health. Therefore, it would be valuable to find eco-friendly and non-antibiotic alternatives to AGPs and to evaluate their effects. However, limited information is available on Clostridium butyricum applied in weanling piglets. In this study, the results showed that Clostridium butyricum administration have positive effects on growth performance, immunity, intestinal morphology, and microbial balance. In conclusion, Clostridium butyricum can be used as a potential alternative to AGPs in weanling piglets.

\begin{abstract}
This study investigated the effects of Clostridium butyricum (C. butyricum) use on growth performance, serum immunity, intestinal morphology, and microbiota as an antibiotic alternative in weaned piglets. Over the course of 28 days, 120 piglets were allocated to four treatments with six replicates of five piglets each. The treatments were: CON (basal diet); AGP (basal diet supplemented with $0.075 \mathrm{~g} / \mathrm{kg}$ chlortetracycline, $0.055 \mathrm{~g} / \mathrm{kg}$ kitasamycin, and $0.01 \mathrm{~g} / \mathrm{kg}$ virginiamycin); CBN (basal diet supplemented with normal dosage of $2.5 \times 10^{8} \mathrm{CFU} / \mathrm{kg}$ C. butyricum); and $\mathrm{CBH}$ (basal diet supplemented with high dosage of $2.5 \times 10^{9} \mathrm{CFU} / \mathrm{kg}$ C. butyricum). Body weight (BW) and feed consumption were recorded at the beginning and on days 14 and 28 of the experiment, and representative feed samples and fresh feces were collected from each pen between days 26 and 28. Average fecal score of diarrhea was visually assessed each morning during the experimental period. On the morning of days 14 and 28, blood samples were collected to prepare serum for immune and antioxidant parameters measurement. One male piglet close to the average group BW was selected from each replicate and was slaughtered on day 21 of the experiment. Intestinal crypt villi, and colonic microbiota and its metabolites short-chain fatty acids were measured. Compared to the CON group, the CBN and AGP groups significantly decreased $(p<0.05)$ the ratio of feed to weight gain by $8.86 \%$ and $8.37 \%$ between days 1 and $14,3.96 \%$ and $13.36 \%$ between days 15 and $28,5.47 \%$ and $11.44 \%$ between days 1 and 28. Dietary treatment with C. butyricum and AGPs significantly decreased the average fecal score during the experimental period $(p<0.05)$. The apparent total tract digestibility of dry matter, organic matter, and total carbohydrates in the $\mathrm{CBH}$ group were higher respectively at
\end{abstract}


$3.27 \%, 2.90 \%$, and $2.97 \%$, than those in the CON or AGP groups ( $p<0.05$ ). Compared to the CON group, the $\mathrm{CBH}$ group significantly increased short-chain fatty acids in colon and villus height in the jejunum $(p<0.05)$. The CBN group had higher serum levels of immunoglobulins, interleukin 2 (IL-2), and glutathione peroxidase (GSH-PX) activity, but lower serum levels of IL-1 $\beta$ and IL-6, and a lower aspartate aminotransferase (AST), alkaline phosphatase (ALP), and gamma-glutamyl transpeptidase $(\gamma-\mathrm{GT})$ activity $(p<0.05)$, while compared to the CON group. Dietary treatment with C. butyricum significantly increased the relative abundance of Streptococcus and Bifidobacterium $(p<0.05)$. In summary, diet with C. butyricum increased the growth performance and benefited the health of weaned piglets.

Keywords: apparent total tract digestibility; average fecal score; intestinal health; serum antioxidant; short-chain fatty acids; weaning stress

\section{Introduction}

Weaning stress can cause dynamic dysbiosis of the microbiota, dyspepsia, retardation of performance, and even death in piglets [1,2], which can result in huge economic losses in livestock production. As an alternative, antibiotic growth promoters (AGPs) have been used as feed additives to prevent weaning-associated disorders, including an increase in harmful microbial activity and post-weaning diarrhea in weaned piglets [3,4]. However, indiscriminate use of AGPs in animal feed poses a threat to human health related to increased antimicrobial resistance in pathogenic and commensal bacteria and residues in animal products and environment. As a result, the European Union has prohibited the use of AGPs in animal feed since January 2006. In July 2019, Proclamation No. 194 was issued by the Ministry of Agriculture and Rural Villages of the People's Republic of China aiming to remove AGP, except in traditional Chinese medicine, beginning January, 2020. Given the trend of banning the use of AGPs as feed additives, it is of high priority to find eco-friendly and effective alternatives to AGPs to compensate for the resulting decrease in animal growth performance.

C. butyricum is a butyric acid-producing Gram-positive anaerobic and spore-forming bacillus with high tolerance to gastrointestinal environment and is isolated from the intestines of healthy humans and animals [5]. This key characteristic ensures that it arrives to the hind gut and plays an important role in regulating intestinal ecological balance. Previous study in Kunming strain mice has indicated that C. butyricum HM754264 by oral gavage at a dosage of $10^{6} \mathrm{CFU} /$ day can obviously promote the proliferation of beneficial bacteria, such as Lactobacillus spp. and Bifidobacterium spp. [6]. In a germ-free mice study, C. butyricum MIYAIRI 588 protected against Escherichia coli O157:H7 infection by decreasing its counts, while mice survival rate was increased by 50\% [7]. Meanwhile, C. butyricum MIYAIRI 588 were capable of inhibiting germination of much larger quantities of Clostridium difficile and toxin protein production in vitro [8]. Moreover, in a 28 days feeding experiment, dietary supplementation with C. butyricum (Strain No. 1.336) in the quantity of spore state of $1 \times 10^{8} \mathrm{CFU} / \mathrm{g}$ increased the average daily gain of crossbred piglets (Duroc $\times$ Landrace $\times$ Large White) [5]. The dosage of C. butyricum MIYAIRI 588 containing $10^{7} \mathrm{CFU} / \mathrm{g}$ of viable spores decreased antibiotic-associated diarrhea, approximately by 9\% [9]. This positive effect may be connected to butyrate, the main metabolite of C. butyricum, which has been shown to control weanling diarrhea [10]. However, there is insufficient research evidence and inconsistent results to support the use of $C$. butyricum in swine production. In addition, C. butyricum appears to carry a risk of bidirectional regulation [11].

The present study evaluated the effects of dietary supplementation with C. butyricum on growth performance, serum immunity, intestinal morphology, and microbiota as a replacement for AGP in weaned piglets. The study aimed to provide a theoretical basis for the application of $C$. butyricum instead of antibiotics in livestock production. 


\section{Materials and Methods}

The study was conducted in January, 2019 at the Inner Mongolia Xingdaye Agriculture and Animal Husbandry Company Limited (N 40 $10^{\prime}$, E $\left.110^{\circ} 26^{\prime}\right)$, Wulanchabu city, Inner Mongolia province, China. All procedures in this experiment were performed in accordance with the recommendations of "Guidelines on Welfare and Ethical Review for Laboratory Animals" [12] approved by the Institutional Animal Care and Use Committee of the Institute of Animal Sciences of the Chinese Academy of Agricultural Sciences.

\subsection{Clostridium Butyricum and Antibiotics}

C. butyricum (China Center for Type Culture Collection CCTCC M 2011384) was obtained by the Academy of Baolai-Leelai Biology Technology (Tai'an, China). The carrier for C. butyricum is cornmeal. An antibiotic premix (75 g chlortetracycline, $55 \mathrm{~g}$ kitasamycin, and $10 \mathrm{~g}$ virginiamycin) was provided by the Inner Mongolia Xingdaye Agriculture and Animal Husbandry Company Limited (Wulanchabu, China).

\subsection{Weanling Piglets, Diets, and Experimental Design}

A total of 120 (48 female and 72 male) crossbred piglets, (Duroc $\times($ Landrace $\times$ Yorkshire)), $8.09 \pm 0.01 \mathrm{~kg}$ of body weight $(\mathrm{BW})$, were weaned at 28 days and used in the experiments. Piglets were randomly allocated to four dietary treatments (six replicates per treatment, with three male and two female piglets per replicate) on the basis of initial BW. The experiment lasted 28 days. A non-medicated corn-soybean basal diet was formulated to meet the National Research Council [13] nutrient requirements for $11-20-\mathrm{kg}$ pigs (Table 1). The dietary treatments included a basal (CON), AGP (basal diet supplemented with $0.075 \mathrm{~g} / \mathrm{kg}$ chlortetracycline, $0.055 \mathrm{~g} / \mathrm{kg}$ kitasamycin, and $0.01 \mathrm{~g} / \mathrm{kg}$ virginiamycin), CBN (basal diet supplemented with $2.5 \times 10^{8} \mathrm{CFU} / \mathrm{kg}$ C. butyricum) [14], and CBH (basal diet supplemented with $2.5 \times 10^{9} \mathrm{CFU} / \mathrm{kg}$ C. butyricum) diets. All piglets were housed in an environmentally controlled room with a hard plastic fully-slotted floor. The adjacent pens were separated by a closed baffle. The room temperature was controlled at $30{ }^{\circ} \mathrm{C}$ throughout the first 2 weeks, and then gradually decreased and kept at $26^{\circ} \mathrm{C}$ until the end of the experiment.

Table 1. Ingredients and chemical composition of experimental diets (as-fed basis).

\begin{tabular}{|c|c|c|c|}
\hline Ingredient, \% & Content & \multicolumn{2}{|c|}{ Nutrient Composition ${ }^{2}, \%$} \\
\hline Extruded corn & 55.00 & $\begin{array}{c}\text { Digestible Energy, } \\
\mathrm{MJ} \mathrm{kg}^{-1}\end{array}$ & 14.50 \\
\hline Soybean meal & 11.30 & Crude protein & 19.10 \\
\hline Extruded soybean & 10.00 & Calcium & 0.82 \\
\hline Fish meal & 5.00 & Total phosphorus & 0.72 \\
\hline Soybean protein concentrate & 4.00 & $\begin{array}{l}\text { Digestible } \\
\text { phosphorus }\end{array}$ & 0.49 \\
\hline Whey powder & 8.00 & Digestible lysine & 1.23 \\
\hline Sucrose & 2.00 & $\begin{array}{l}\text { Digestible } \\
\text { methionine }\end{array}$ & 0.36 \\
\hline Soy oil & 1.50 & $\begin{array}{l}\text { Digestible } \\
\text { threonine }\end{array}$ & 0.74 \\
\hline Dicalcium phosphate & 1.00 & $\begin{array}{l}\text { Digestible } \\
\text { tryptophan }\end{array}$ & 0.20 \\
\hline Limestone & 0.50 & & \\
\hline Salt & 0.20 & & \\
\hline Chromium oxide & 0.25 & & \\
\hline L-Lysine-HCl & 0.30 & & \\
\hline DL-Methionine & 0.20 & & \\
\hline L-Threonine & 0.15 & & \\
\hline L-Tryptophan & 0.10 & & \\
\hline Vitamin and mineral mixture ${ }^{1}$ & 0.50 & & \\
\hline
\end{tabular}

${ }^{1}$ Provided per kg of diet: vitamin A, $2200 \mathrm{IU}$; vitamin $\mathrm{D}_{3}, 220 \mathrm{IU}$; vitamin $\mathrm{E}, 11 \mathrm{IU}$; vitamin $\mathrm{K}_{3}, 0.5 \mathrm{mg}$; vitamin $\mathrm{B}_{12}, 0.015 \mathrm{mg}$; riboflavin, $4 \mathrm{mg}$; niacin, $30 \mathrm{mg}$; pantothenic acid, $10 \mathrm{mg}$; choline chloride, $400 \mathrm{mg}$; folic acid, $0.3 \mathrm{mg}$; thiamine, $1.5 \mathrm{mg}$; vitamin $\mathrm{B}_{6}, 3 \mathrm{mg}$; biotin, $0.1 \mathrm{mg}$; zinc, $100 \mathrm{mg}$; manganese, $4 \mathrm{mg}$; iron, $84 \mathrm{mg}$; copper, $6 \mathrm{mg}$; iodine, $0.14 \mathrm{mg}$; and selenium, $0.35 \mathrm{mg} .{ }^{2}$ Nutrient levels are calculated. 


\subsection{Sample Collection and Measurements}

\subsubsection{Growth Performance}

Taking each repeat as one unit, BW was recorded at the beginning of each experiment and on days 14 and 28. Feed consumption was recorded on days 14 and 28 to calculate the average daily gain (ADG), average daily feed intake (ADFI), and the ratio of feed to weight gain (F/G).

Clinical signs of diarrhea were visually assessed each morning by observers blinded to the treatments using a five-grade scoring system [15]: $1=$ well-formed feces, $2=$ slightly soft feces, $3=$ soft and partially formed feces, $4=$ loose and semiliquid feces, and $5=$ watery feces. Then the daily average fecal score per replicate was calculated. Average fecal score per replicate from days 1-14, 15-28, and 1-28 were calculated and used for further statistical analysis.

\subsubsection{Apparent Nutrient Digestibility}

Representative feed samples of $1.0 \mathrm{~kg}$ were collected at the end of the experiment. Between days 26 and 28, approximately $200 \mathrm{~g}$ of fresh feces were collected from each pen and immediately frozen at $-20{ }^{\circ} \mathrm{C}$. Each three-day collection of feces was pooled by pen, dried at $65{ }^{\circ} \mathrm{C}$ for $72 \mathrm{~h}$, and subsequently ground to pass through a 1-mm sieve until further analysis. Crude protein (CP), ether extract (EE), ash, and dry matter (DM) of feed and fecal samples were measured according to the AOAC [16] methods. Diet and feces chromium concentrations were determined by an automatic absorption spectrophotometer (Z-5000; Hitachi, Tokyo, Japan) based on the procedures described by previous study [17]. In addition, total carbohydrates and organic matter (OM) were calculated using the following equation: total carbohydrates $=\mathrm{DM}-\mathrm{CP}-\mathrm{EE}-\mathrm{ash}, \mathrm{OM}=1-$ ash [18]. Apparent total tract digestibility nutrient $(\mathrm{ATTD})=1-\left(\mathrm{Cr}_{\text {diet }} \times \mathrm{Nutrient}_{\text {feces }}\right) /\left(\mathrm{Cr}_{\text {feces }} \times\right.$ Nutrient $\left._{\text {diet }}\right)$.

\subsubsection{SCFAs Concentration in Colon}

After fasting overnight on day 21, one male piglet close to the average group BW was selected from each replicate and was slaughtered $5 \mathrm{~min}$ after injecting the anesthetic. Colonic digesta samples were collected from slaughtered piglets. Short chain fatty acids (SCFAs), including acetate, propionate, butyrate, valerate, isobutyrate, and isovalerate, were quantified by an external standard method using gas chromatography (GC) as described by previous study [19,20]. Briefly, 1.5-g colonic chyme samples were added to screw-capped tubes with $6 \mathrm{~mL}$ of distilled water. After mixing overnight at $4{ }^{\circ} \mathrm{C}$ and centrifugation at $1500 \mathrm{r} / \mathrm{min}$ for $10 \mathrm{~min}$ at $4{ }^{\circ} \mathrm{C}, 2 \mathrm{~mL}$ of supernatant from each sample were transferred to another centrifuge tube, and $400 \mu \mathrm{L}$ of meta-phosphoric acid $(25 \% v / v)$ were added to remove the protein. The samples were then centrifuged at $12,000 \mathrm{r} / \mathrm{min}$ for $10 \mathrm{~min}$ at $4{ }^{\circ} \mathrm{C}$. The resulting supernatants ( $1 \mathrm{~mL}$ each) were transferred into gas chromatography sample bottles and analyzed using an Agilent 6890N GC (Palo Alto, CA, USA) coupled to a flame-ionization detector with helium used as the carrier gas. An Agilent FFAP column $(30 \mathrm{~m} \times 0.53 \mathrm{~mm}$ i.d. $\times 1.00 \mu \mathrm{m}$ (film thickness) $)$ was installed for analysis, with a constant flow rate of $4.0 \mathrm{~mL} / \mathrm{min}$. Splitless injection volume was $0.2 \mu \mathrm{L}$ of sample. The injector and detector temperature were $220^{\circ} \mathrm{C}$ and $240^{\circ} \mathrm{C}$, respectively. The GC oven temperature was held at $90^{\circ} \mathrm{C}$ for $1 \mathrm{~min}$ and then increased to $190^{\circ} \mathrm{C}$ at a rate of $20^{\circ} \mathrm{C} / \mathrm{min}$ and held for $3 \mathrm{~min}$. Samples were run in triplicate, with a coefficient of variation less than $15 \%$ within triplicate samples used for quality control $[19,20]$.

\subsubsection{Immunity and Antioxidant Indices in Serum}

On the morning of days 14 and 28, 5-mL blood samples were collected from one male piglet from each replicate via jugular vein puncture into a vacutainer. After $2 \mathrm{~h}$, blood samples were centrifuged at $3000 \times g$ at $4{ }^{\circ} \mathrm{C}$ for $10 \mathrm{~min}$ to recover the serum, which was stored at $-20{ }^{\circ} \mathrm{C}$ until further analysis. Serum immunoglobulins (IgG, IgA, and IgM), interleukins (IL-1 $\beta$, IL-2, and IL-6), and tumor necrosis factor (TNF- $\alpha$ ) were measured using an ELISA kit (Shanghai Enzyme-linked Biotechnology, Co., Ltd., Shanghai, China). Serum antioxidant indices, including total antioxidant capacity (T, -AOC), 
glutathione peroxidase (GSH-PX), inhibiting ability of hydroxyl radical $(\mathrm{OH})$, superoxide dismutase (SOD), hydrogen peroxide $\left(\mathrm{H}_{2} \mathrm{O}_{2}\right)$, nitric oxide (NO), and Cholinesterase (CHE) were measured using biochemical methods following manufacturer instructions provided for each reagent kit (Nanjing Jiancheng Bioengineering Institute, Nanjing, China). Serum alanine transaminase (ALT), aspartate aminotransferase (AST), alkaline phosphatase (ALP), and gamma-glutamyl transpeptidase ( $\gamma$-GT) were measured with an automatic biochemical analyzer (KHB-1280, Shanghai, China).

\subsubsection{Intestinal Morphology}

After slaughtering piglets, the intestines were divided into three parts, including duodenum, jejunum, and ileum, according to the method described by previous study [21]. Then, the middle of duodenum, jejunum, and ileum with $2 \mathrm{~cm}$ long intestinal canal was respectively collected, slightly washed with saline, and immediately fixed in $4 \%$ formalin, stored at $4{ }^{\circ} \mathrm{C}$. The intestinal specimens were embedded in paraffin, sectioned $(4 \mu \mathrm{m})$, and stained with hematoxylin, eosin, and periodic acid-Schiff. Three intact crypt villi in each sample were selected, and villus height and adjoining crypt depth were determined using an image analysis system (Version 1, Leica Imaging Systems Ltd., Cambridge, UK) [22]. Villus height was measured from the apex to the base of the villus crypt junction along its axis, and crypt depth was defined as the depth of the invagination between adjacent villi [23]. The ratio of villus height to crypt depth was calculated.

\subsubsection{Microbiota in Colon}

Colonic digesta samples were collected from slaughtered piglets and immediately stored at $-80^{\circ} \mathrm{C}$. Bacterial genomic DNA was extracted from each sample (Qiagen DNA Stool Mini Kit, Duesseldorf, Germany). DNA was quantified with a NanoDrop 2000 spectrophotometer (Thermo Scientific, Wilmington, NC, USA) and further assessed by running on $1 \%$ agarose gels. The V3-V4 hypervariable region of $16 \mathrm{~S}$ rRNA genes was amplified using specific primer pairs (forward 5'-ACTCCTACGGGAGGCAGCA-3' and reverse 5'-GGACTACHVGGGTWTCTAAT-3') with barcodes to construct the sequencing libraries (TruSeq ${ }^{\circledR}$ DNA PCR-Free Sample Prep Kit, Illumina, San Diego, CA, USA). The qualified DNA libraries were loaded in a NovaSeq platform with $2 \times 250 \mathrm{bp}$ paired-end sequencing. The paired-end reads were obtained and merged using FLASH software (V1.2.7, http://ccb.jhu.edu/software/FLASH/). Operational taxonomic units (OTUs) with a 97\% identity were gathered with Uparse (ver. 7.1, http://drive5.com/uparse/). Taxonomic annotation was performed using the Mothur algorithm (70\% confidence) with the Silva Database (http://www.arb-silva.de/). Taxonomic composition of the bacterial community was then analyzed.

\subsection{Statistical Analysis}

Data were analyzed using one-way analysis of variance according to the comparative average and general line model procedures in SPSS 22.0 (IBM Corp., Armonk, NY, USA). The differences among treatment means for the growth performance, serum indices, ATTD, SCFAs concentration, and relative abundance of microbiota were analyzed using Duncan's multiple-range test and least significant difference (LSD) post hoc tests. $p$-values $<0.05$ were considered significant.

\section{Results}

\subsection{Growth Performance}

Compared to the CON group, dietary supplementation with C. butyricum $\left(2.5 \times 10^{8} \mathrm{CFU} / \mathrm{kg}\right)$ increased the feed efficiency by significantly decreasing F/G $(p<0.05)$ and decreased average fecal score during days $1-14,15-28$, and 1-28 $(p<0.05$, Table 2$)$. Supplementation with $C$. butyricum $\left(2.5 \times 10^{9} \mathrm{CFU} / \mathrm{kg}\right)$ and AGPs significantly decreased the F/G during days $1-14(p<0.05)$, and dietary with AGPs significantly decreased average fecal score during days 1-14, 15-28, and 1-28 $(p<0.05)$ compared to the CON group. 
Table 2. Effect of dietary C. butyricum on growth performance and average fecal score in weaned piglets $\left(\right.$ mean $\left.\pm \mathrm{SE}^{2}\right)$.

\begin{tabular}{|c|c|c|c|c|c|}
\hline \multirow{2}{*}{ Item } & \multicolumn{4}{|c|}{ Dietary Treatments ${ }^{1}$} & \multirow{2}{*}{$p$-Value } \\
\hline & $\mathrm{CON}$ & AGP & CBN & $\mathrm{CBH}$ & \\
\hline \multicolumn{6}{|c|}{ Body weight, $\mathrm{kg}$} \\
\hline Initial & $8.09 \pm 0.01$ & $8.09 \pm 0.01$ & $8.10 \pm 0.005$ & $8.09 \pm 0.01$ & 0.376 \\
\hline Day 14 & $10.18 \pm 0.24$ & $10.43 \pm 0.14$ & $10.24 \pm 0.16$ & $10.15 \pm 0.10$ & 0.293 \\
\hline Day 28 & $14.11 \pm 0.49$ & $14.57 \pm 0.55$ & $14.33 \pm 0.17$ & $14.04 \pm 0.33$ & 0.416 \\
\hline \multicolumn{6}{|c|}{ Days 1-14 } \\
\hline $\mathrm{ADFI}^{3}, \mathrm{~kg}$ & $0.325 \pm 0.035$ & $0.333 \pm 0.016$ & $0.303 \pm 0.019$ & $0.294 \pm 0.016$ & 0.284 \\
\hline $\mathrm{ADG}^{3}, \mathrm{~kg}$ & $0.161 \pm 0.019$ & $0.180 \pm 0.011$ & $0.164 \pm 0.012$ & $0.158 \pm 0.007$ & 0.302 \\
\hline $\mathrm{F} / \mathrm{G}^{3}$ & $2.03 \pm 0.07^{\mathrm{a}}$ & $1.86 \pm 0.05^{b}$ & $1.85 \pm 0.05^{b}$ & $1.85 \pm 0.03^{b}$ & 0.035 \\
\hline Average fecal score & $2.22 \pm 0.07^{\mathrm{a}}$ & $1.67 \pm 0.12^{\mathrm{c}}$ & $1.87 \pm 0.02^{b, c}$ & $2.02 \pm 0.07^{\mathrm{a}, \mathrm{b}}$ & 0.001 \\
\hline \multicolumn{6}{|c|}{ Days $15-28$} \\
\hline ADFI, kg & $0.513 \pm 0.036$ & $0.517 \pm 0.043$ & $0.466 \pm 0.019$ & $0.468 \pm 0.015$ & 0.304 \\
\hline $\mathrm{ADG}, \mathrm{kg}$ & $0.256 \pm 0.025$ & $0.271 \pm 0.033$ & $0.268 \pm 0.016$ & $0.246 \pm 0.015$ & 0.510 \\
\hline $\mathrm{F} / \mathrm{G}$ & $2.02 \pm 0.11^{\mathrm{a}}$ & $1.94 \pm 0.09^{a, b}$ & $1.75 \pm 0.06^{b}$ & $1.92 \pm 0.08^{a, b}$ & 0.051 \\
\hline Average fecal score & $2.09 \pm 0.15^{\mathrm{a}}$ & $1.69 \pm 0.09^{b}$ & $1.70 \pm 0.07^{\mathrm{b}}$ & $1.97 \pm 0.09 \mathrm{a}, \mathrm{b}$ & 0.034 \\
\hline \multicolumn{6}{|c|}{ Days 1-28 } \\
\hline ADFI, kg & $0.416 \pm 0.033$ & $0.422 \pm 0.026$ & $0.382 \pm 0.011$ & $0.380 \pm 0.014$ & 0.254 \\
\hline $\mathrm{ADG}, \mathrm{kg}$ & $0.207 \pm 0.018$ & $0.224 \pm 0.020$ & $0.214 \pm 0.006$ & $0.202 \pm 0.011$ & 0.352 \\
\hline $\mathrm{F} / \mathrm{G}$ & $2.01 \pm 0.07^{\mathrm{a}}$ & $1.90 \pm 0.06^{\mathrm{a}, \mathrm{b}}$ & $1.78 \pm 0.03^{b}$ & $1.89 \pm 0.05^{a, b}$ & 0.067 \\
\hline Average fecal score & $2.16 \pm 0.07^{\mathrm{a}}$ & $1.67 \pm 0.10^{b}$ & $1.79 \pm 0.04^{b}$ & $2.00 \pm 0.07^{\mathrm{a}}$ & 0.001 \\
\hline
\end{tabular}

${ }_{\mathrm{a}-\mathrm{c}}$ Different superscripts within a row indicate a significant difference $(p<0.05) .{ }^{1}$ Dietary treatments: CON $=$ basal diet; $\mathrm{AGP}=$ basal diet supplemented with $0.075 \mathrm{~g} / \mathrm{kg}$ chlortetracycline, $0.055 \mathrm{~g} / \mathrm{kg}$ kitasamycin, and $0.01 \mathrm{~g} / \mathrm{kg}$ virginiamycin; $\mathrm{CBN}=$ basal diet supplemented with $2.5 \times 10^{8} \mathrm{CFU} / \mathrm{kg}$ C. butyricum; $\mathrm{CBH}=$ basal diet supplemented with $2.5 \times 10^{9} \mathrm{CFU} / \mathrm{kg} \mathrm{C}$. butyricum. ${ }^{2} \mathrm{SE}$ : standard error of the mean. Each treatment group contains six replicates $(n=6)$, and each replicate includes five piglets. ${ }^{3}$ ADFI: average daily feed intake; ADG: average daily gain; F/G: ratio of feed to weight gain.

\subsection{Apparent Nutrient Digestibility}

The CBH group significantly increased ATTD of DM, OM, and total carbohydrates compared to the CON group $(p<0.05)$ and significantly increased ATTD of OM and total carbohydrates in comparison to the CBN group ( $p<0.05$, Table 3). While ATTD of EE in the CBN group increased by approximately $7.00 \%$ compared to the CON and AGP groups, no significant differences were found between the CBN and CON, AGP, or CBH groups $(p>0.05)$.

Table 3. Effect of dietary C. butyricum on feed nutrient ATTD (mean $\pm \mathrm{SE}^{2}$, \%).

\begin{tabular}{|c|c|c|c|c|c|}
\hline \multirow{2}{*}{ Item } & \multicolumn{4}{|c|}{ Dietary Treatments ${ }^{1}$} & \multirow{2}{*}{$p$-Value } \\
\hline & $\mathrm{CON}$ & AGP & CBN & $\mathrm{CBH}$ & \\
\hline Dry Matter & $81.99 \pm 0.43^{a}$ & $81.96 \pm 0.72^{a}$ & $82.90 \pm 0.63^{a, b}$ & $84.67 \pm 0.60^{b}$ & 0.024 \\
\hline Crude Protein & $76.42 \pm 1.47$ & $75.71 \pm 1.61$ & $76.00 \pm 1.36$ & $77.44 \pm 1.46$ & 0.460 \\
\hline Ether Extract & $62.90 \pm 1.20$ & $62.51 \pm 1.13$ & $67.11 \pm 2.75$ & $66.55 \pm 1.33$ & 0.128 \\
\hline Organic Matter & $83.75 \pm 0.50^{a}$ & $83.43 \pm 0.80^{a}$ & $84.11 \pm 0.72^{a}$ & $86.18 \pm 0.58^{b}$ & 0.044 \\
\hline Total Carbohydrates & $88.00 \pm 0.35^{\mathrm{a}}$ & $87.72 \pm 0.50^{\mathrm{a}}$ & $88.30 \pm 0.53^{a}$ & $90.61 \pm 0.17^{b}$ & 0.001 \\
\hline
\end{tabular}




\subsection{SCFAs Concentration in Colon}

Compared to CON group, the CBH group significantly increased the concentration of acetic, propionic, and butyric acids and total SCFAs in colon $(p<0.05$, Table 4$)$. While the CBN group significantly increased the acetic acid, the isobutyric, valeric, isovaleric acids were decreased $(p<0.05)$. Concentrations of propionic, butyric, isobutyric, valeric, and isobaleric acids in the CBN group were lower than those in the CBH group $(p<0.05)$. However, there were no significant differences in total SCFAs between the CBN and CBH groups $(p>0.05)$.

Table 4. Effect of dietary C. butyricum on short-chain fatty acids in colonic chyme (mean $\left.\pm \mathrm{SE}^{2}, \mu \mathrm{mol} / \mathrm{g}\right)$.

\begin{tabular}{|c|c|c|c|c|c|}
\hline \multirow{2}{*}{ Item } & \multicolumn{4}{|c|}{ Dietary Treatments ${ }^{1}$} & \multirow{2}{*}{$p$-Value } \\
\hline & $\mathrm{CON}$ & AGP & CBN & $\mathrm{CBH}$ & \\
\hline Acetic acid & $55.66 \pm 5.10^{a}$ & $60.78 \pm 3.38^{a, b}$ & $68.23 \pm 1.70^{b, c}$ & $71.66 \pm 1.57^{c}$ & 0.008 \\
\hline Propionic acid & $19.90 \pm 0.80^{\mathrm{a}}$ & $21.37 \pm 0.72^{\mathrm{a}}$ & $21.82 \pm 1.31^{\mathrm{a}}$ & $24.90 \pm 1.16^{b}$ & 0.017 \\
\hline Butyric acid & $7.87 \pm 0.93^{\mathrm{a}}$ & $7.35 \pm 0.38^{a}$ & $7.81 \pm 0.61^{\mathrm{a}}$ & $10.86 \pm 1.28^{b}$ & 0.021 \\
\hline Isobutyric acid & $0.90 \pm 0.07^{b}$ & $0.40 \pm 0.06^{\mathrm{a}}$ & $0.55 \pm 0.07^{\mathrm{a}}$ & $0.80 \pm 0.08^{b}$ & $<0.01$ \\
\hline Valeric acid & $1.97 \pm 0.26^{b}$ & $0.99 \pm 0.09^{a}$ & $1.16 \pm 0.22^{\mathrm{a}}$ & $2.16 \pm 0.19^{b}$ & $<0.01$ \\
\hline Isovaleric acid & $1.17 \pm 0.09^{b}$ & $0.61 \pm 0.05^{\mathrm{a}}$ & $0.75 \pm 0.11^{\mathrm{a}}$ & $1.07 \pm 0.09^{b}$ & $<0.01$ \\
\hline Total short chain fatty acids & $87.47 \pm 8.06^{\mathrm{a}}$ & $91.50 \pm 4.46^{\mathrm{a}}$ & $100.32 \pm 2.40^{a, b}$ & $111.45 \pm 9.43^{b}$ & 0.006 \\
\hline
\end{tabular}

\subsection{Immunity and Antioxidant Indices in Serum}

On day 14, the CBN group exhibited a higher IgM serum level, inhibiting hydroxyl radical ability and GSH-PX activity trend $(p=0.066)$, while the AGP group showed a lower TNF $\alpha$ serum level in comparison to the CON group ( $p<0.05$, Table 5). On day 28, compared to the CON group, the CBN group significantly increased serum levels of IgA, IgM, IgG, and IL-2 and GSH-PX activity, inhibited hydroxyl radical ability, and decreased IL-1 $\beta$ and IL-6 serum levels $(p<0.05)$. Serum IgG level and hydroxyl radical inhibition ability in the CBN group was higher, while concentration of NO was lower than that in the AGP group $(p<0.05)$. The CBH group also modestly increased serum levels of immunoglobulins (Igs) and decreased the levels of pro-inflammatory factors, including IL-1 $\beta$, IL-6, and TNF $\alpha$, on day 28 compared to the CON group $(p>0.05)$. Piglets in the AGP, CBN, and CBH groups had lower ALP, $\gamma-\mathrm{GT}$, and CHE activities compared with piglets in the CON group $(p<0.05)$ on day 14. In addition, $\gamma$-GT and $\mathrm{CHE}$ in the $\mathrm{CBN}$ and $\mathrm{CBH}$ groups were lower than those in the AGP group $(p<0.05)$. On day 28, AST and $\gamma-\mathrm{GT}$ activity in the CON, AGP, and CBN groups were lower than those in the CBH group $(p<0.05)$, and AST activity in the CBN group was lower than that in the CON and AGP groups $(p<0.05)$. Piglets in the CON and CBN groups had lower CHE activity than piglets in the AGP and CBH groups $(p<0.05)$.

Table 5. Effect of dietary C. butyricum on serum immunity and antioxidant ability (mean $\pm \mathrm{SE}^{2}$ ).

\begin{tabular}{|c|c|c|c|c|c|}
\hline Item & \multicolumn{4}{|c|}{ Dietary Treatments ${ }^{1}$} & $p$-Value \\
\hline \multicolumn{6}{|c|}{ Day 14} \\
\hline $\operatorname{Ig} \mathrm{A}^{3}, \mu g \mathrm{~mL}^{-1}$ & $75.46 \pm 6.19^{a}$ & $77.76 \pm 6.73^{\mathrm{a}, \mathrm{b}}$ & $90.16 \pm 4.97^{\mathrm{a}, \mathrm{b}}$ & $93.33 \pm 5.88^{b}$ & 0.047 \\
\hline $\operatorname{IgM}^{3}, \mathrm{mg} \mathrm{mL}^{-1}$ & $1.58 \pm 0.17^{\mathrm{a}}$ & $2.01 \pm 0.18^{\mathrm{a}}$ & $2.60 \pm 0.13^{b}$ & $1.93 \pm 0.10^{\mathrm{a}}$ & 0.001 \\
\hline $\mathrm{IgG}^{3}, \mathrm{mg} \mathrm{mL}^{-1}$ & $5.24 \pm 0.19$ & $5.46 \pm 0.18$ & $5.70 \pm 0.17$ & $5.35 \pm 0.23$ & 0.142 \\
\hline $\mathrm{IL}^{-6}{ }^{3}, \mathrm{pg} \mathrm{mL} \mathrm{m}^{-1}$ & $275.05 \pm 5.74$ & $267.11 \pm 8.36$ & $264.31 \pm 6.33$ & $273.59 \pm 6.98$ & 0.327 \\
\hline $\mathrm{TNF} \alpha^{3}, \mathrm{pg} \mathrm{mL}^{-1}$ & $58.46 \pm 1.74^{\mathrm{a}}$ & $53.10 \pm 0.97^{b}$ & $55.99 \pm 1.13^{\mathrm{a}, \mathrm{b}}$ & $54.78 \pm 2.36^{\mathrm{a}, \mathrm{b}}$ & 0.032 \\
\hline GSH-PX ${ }^{3}, \mathrm{U} \mathrm{mL}^{-1}$ & $582.48 \pm 35.98$ & $667.53 \pm 30.20$ & $674.93 \pm 24.48$ & $584.00 \pm 31.07$ & 0.066 \\
\hline
\end{tabular}


Table 5. Cont.

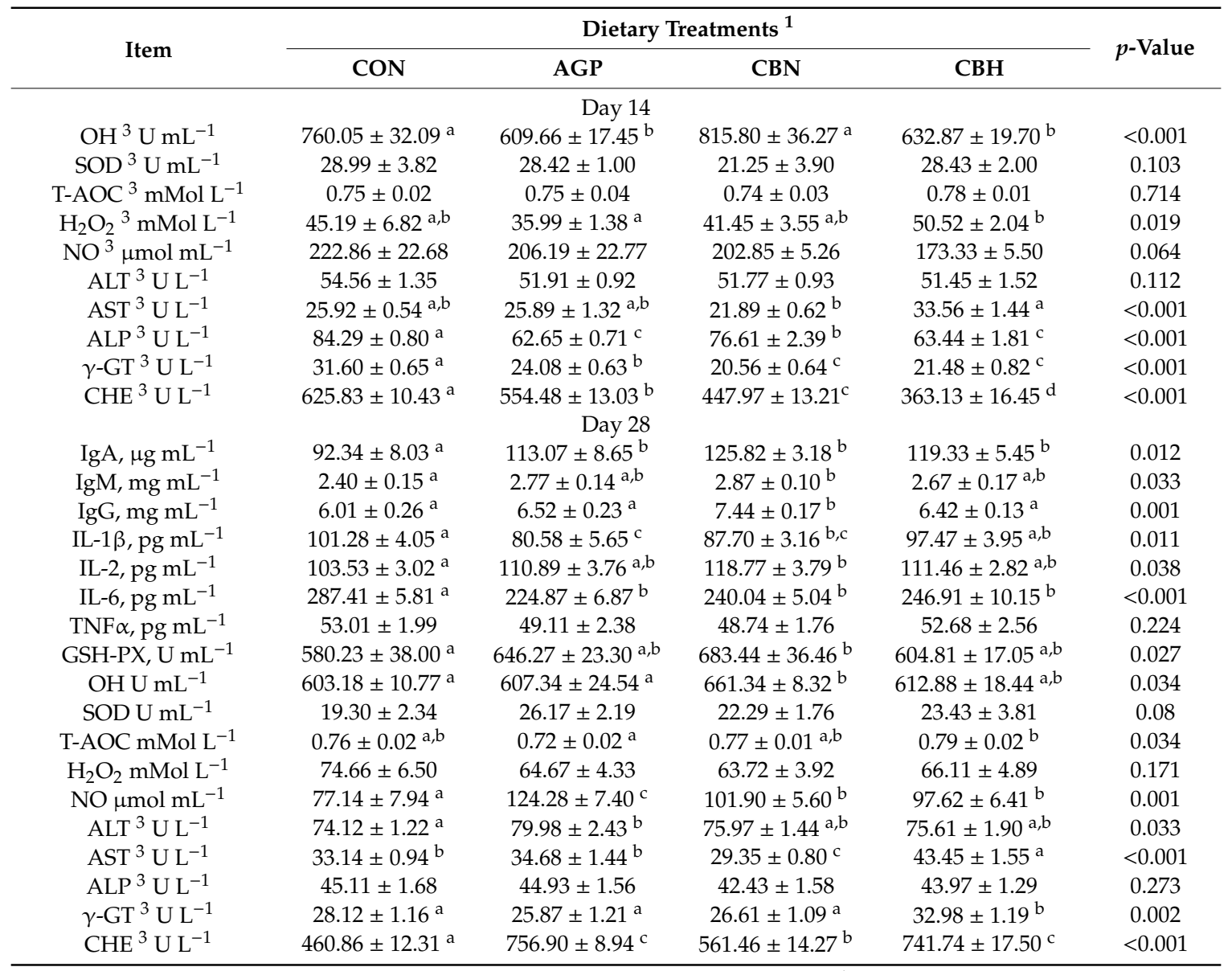

${ }^{\mathrm{a}-\mathrm{c}}$ Different superscripts within a row indicate a significant difference $(p<0.05) .{ }^{1}$ Dietary treatments: CON $=$ basal diet; AGP = basal diet supplemented with $0.075 \mathrm{~g} / \mathrm{kg}$ chlortetracycline, $0.055 \mathrm{~g} / \mathrm{kg}$ kitasamycin, and $0.01 \mathrm{~g} / \mathrm{kg}$ virginiamycin; $\mathrm{CBN}=$ basal diet supplemented with $2.5 \times 10^{8} \mathrm{CFU} / \mathrm{kg}$ C. butyricum; $\mathrm{CBH}=$ basal diet supplemented with $2.5 \times 10^{9} \mathrm{CFU} / \mathrm{kg} \mathrm{C}$. butyricum. ${ }^{2} \mathrm{SE}$ : standard error of the mean. Each treatment group contains six replicates $(n=6)$, and each replicate includes one piglet. ${ }^{3}$ IgA immunoglobulin A; IgM immunoglobulin M; IgG immunoglobulin G; IL-1 $\beta$, interleukin $1 \beta$; IL-2, interleukin 2; IL-6, interleukin 6; TNF- $\alpha$, tumor necrosis factor $\alpha$; GSH-PX, glutathione peroxidase; $\mathrm{OH}$, inhibiting ability of hydroxyl radical; SOD, superoxide dismutase; T-AOC, total antioxidant capacity; $\mathrm{H}_{2} \mathrm{O}_{2}$, hydrogen peroxide; $\mathrm{NO}$, nitric oxide; $\mathrm{ALT}$, alanine transaminase; AST, aspartate aminotransferase; ALP, alkaline phosphatase; $\gamma$-GT, gamma-glutamyl transpeptidase; CHE, Cholinesterase.

\subsection{Intestinal Morphology}

Dietary treatment with the $\mathrm{CBH}$ diet significantly increased villus height and crypt depth of the jejunum compared to the CON group ( $p<0.05$, Table 6). Villus height of the jejunum and ileum in the CBN group was slightly higher than that in the $\mathrm{CON}$ group, with no differences present between the $\mathrm{CBN}$ and $\mathrm{CBH}$ groups $(p>0.05)$.

Table 6. Effect of dietary C. butyricum on the intestinal morphology of piglets (mean $\pm \mathrm{SE}^{2}$ ).

\begin{tabular}{|c|c|c|c|c|c|}
\hline \multirow{2}{*}{ Item } & \multicolumn{4}{|c|}{ Dietary Treatments ${ }^{1}$} & \multirow{2}{*}{$p$-Value } \\
\hline & $\mathrm{CON}$ & AGP & CBN & $\mathrm{CBH}$ & \\
\hline \multicolumn{6}{|c|}{ Duodenum } \\
\hline Villus height, $\mu \mathrm{m}$ & $651.99 \pm 13.56$ & $670.89 \pm 8.61$ & $656.67 \pm 9.29$ & $680.22 \pm 19.32$ & 0.183 \\
\hline Crypt depth, $\mu \mathrm{m}$ & $288.83 \pm 9.96$ & $293.41 \pm 8.42$ & $299.29 \pm 6.82$ & $304.47 \pm 10.00$ & 0.266 \\
\hline Villus height/Crypt depth & $2.27 \pm 0.05$ & $2.30 \pm 0.06$ & $2.20 \pm 0.05$ & $2.25 \pm 0.07$ & 0.309 \\
\hline
\end{tabular}


Table 6. Cont.

\begin{tabular}{|c|c|c|c|c|c|}
\hline \multirow{2}{*}{ Item } & \multicolumn{4}{|c|}{ Dietary Treatments ${ }^{1}$} & \multirow{2}{*}{$p$-Value } \\
\hline & $\mathrm{CON}$ & AGP & CBN & $\mathrm{CBH}$ & \\
\hline \multicolumn{6}{|c|}{ Jejunum } \\
\hline Villus height, $\mu \mathrm{m}$ & $658.99 \pm 19.02^{\mathrm{a}}$ & $695.39 \pm 14.33^{a, b}$ & $694.36 \pm 15.66^{\mathrm{a}, \mathrm{b}}$ & $727.42 \pm 11.10^{b}$ & 0.030 \\
\hline Crypt depth, $\mu \mathrm{m}$ & $276.35 \pm 6.32^{\mathrm{a}}$ & $309.53 \pm 13.10^{a, b}$ & $300.30 \pm 15.01^{\mathrm{a}, \mathrm{b}}$ & $316.41 \pm 11.11^{b}$ & 0.022 \\
\hline Villus height/Crypt depth & $2.38 \pm 0.06$ & $\begin{array}{r}2.27 \pm 0.09 \\
\text { Ileum }\end{array}$ & $2.35 \pm 0.09$ & $2.33 \pm 0.09$ & 0.393 \\
\hline Villus height, $\mu \mathrm{m}$ & $568.06 \pm 12.61$ & $584.11 \pm 22.18$ & $602.39 \pm 25.57$ & $605.67 \pm 23.70$ & 0.270 \\
\hline Crypt depth, $\mu \mathrm{m}$ & $251.42 \pm 9.07$ & $245.86 \pm 8.80$ & $261.72 \pm 14.49$ & $252.95 \pm 9.01$ & 0.344 \\
\hline Villus height/Crypt depth & $2.28 \pm 0.08$ & $2.38 \pm 0.08$ & $2.35 \pm 0.12$ & $2.40 \pm 0.07$ & 0.400 \\
\hline
\end{tabular}

\subsection{Microbiota in Colon}

The dominant phyla included Firmicutes, Proteobacteria, and Bacteroidetes, which represented more than $57.15,6.56$, and $14.73 \%$ of the total community, respectively (Table 7 ). Compared to the CON group, the relative abundance of Firmicutes and Proteobacteria in the CBN group was decreased by approximately 10.24 and $54.78 \%$, respectively $(p>0.05)$, while the relative abundance of Bacteroidetes was increased by $31.70 \%(p>0.05)$. Of the 50 most dominant genera (18 genera were listed), dietary treatment with $C$. butyricum significantly increased the relative abundance of Streptococcus and Bifidobacterium $(p<0.05)$ and slightly increased the relative abundance of Butyricicoccus $(p>0.05)$. The relative abundance of Sarcina, Blautia, and Actinobacillus $(p>0.05)$ was decreased compared to that in the CON and AGP groups.

Table 7. Effect of dietary C. butyricum on the relative abundance (\%) of microbiota in the colonic chyme of piglets (mean $\pm \mathrm{SE}^{2}$ ).

\begin{tabular}{|c|c|c|c|c|c|}
\hline \multirow{2}{*}{ Phyla/Genera } & \multicolumn{4}{|c|}{ Dietary Treatments ${ }^{1}$} & \multirow{2}{*}{$p$-Value } \\
\hline & $\mathrm{CON}$ & AGP & $\mathrm{CBN}$ & $\mathrm{CBH}$ & \\
\hline Firmicutes (phylum) & $63.67 \pm 7.82$ & $66.06 \pm 2.52$ & $57.15 \pm 3.86$ & $69.07 \pm 5.37$ & 0.158 \\
\hline Sarcina & $8.61 \pm 3.34$ & $3.86 \pm 1.28$ & $3.70 \pm 0.85$ & $4.89 \pm 1.71$ & 0.131 \\
\hline Subdoligranulum & $5.72 \pm 2.58$ & $2.54 \pm 0.88$ & $2.24 \pm 0.23$ & $2.55 \pm 0.82$ & 0.129 \\
\hline Streptococcus & $4.52 \pm 1.25^{\mathrm{a}}$ & $7.81 \pm 1.84^{\mathrm{a}, \mathrm{b}}$ & $8.51 \pm 2.26^{\mathrm{a}, \mathrm{b}}$ & $11.46 \pm 2.34^{b}$ & 0.022 \\
\hline Blautia & $6.20 \pm 1.93$ & $5.97 \pm 1.30$ & $3.67 \pm 1.32$ & $6.73 \pm 2.42$ & 0.286 \\
\hline Butyricicoccus & $2.01 \pm 0.67$ & $1.33 \pm 0.25$ & $2.48 \pm 0.82$ & $2.24 \pm 0.70$ & 0.266 \\
\hline Megamonas & $0.10 \pm 0.07$ & $0.79 \pm 0.75$ & $0.007 \pm 0.002$ & $0.02 \pm 0.01$ & 0.189 \\
\hline Phascolarctobacterium & $1.25 \pm 0.32$ & $0.92 \pm 0.21$ & $1.62 \pm 0.39$ & $1.46 \pm 0.60$ & 0.279 \\
\hline Mitsuokella & $0.22 \pm 0.08$ & $0.60 \pm 0.57$ & $0.17 \pm 0.09$ & $0.05 \pm 0.02$ & 0.238 \\
\hline Anaerostipes & $0.12 \pm 0.08$ & $1.15 \pm 0.17$ & $0.92 \pm 0.16$ & $1.75 \pm 0.49$ & 0.180 \\
\hline Roseburia & $1.80 \pm 0.50$ & $1.04 \pm 0.32$ & $1.01 \pm 0.57$ & $1.26 \pm 0.40$ & 0.190 \\
\hline Faecalibacterium & $0.69 \pm 0.23$ & $0.94 \pm 0.17$ & $0.40 \pm 0.07$ & $0.77 \pm 0.42$ & 0.188 \\
\hline Peptococcus & $0.33 \pm 0.09$ & $0.41 \pm 0.08$ & $0.54 \pm 0.12$ & $0.40 \pm 0.07$ & 0.175 \\
\hline Turicibacter & $0.01 \pm 0.006$ & $0.008 \pm 0.004$ & $0.05 \pm 0.03$ & $0.26 \pm 0.17$ & 0.078 \\
\hline Proteobacteria (phylum) & $14.95 \pm 8.72$ & $7.98 \pm 1.90$ & $6.76 \pm 1.74$ & $6.56 \pm 2.28$ & 0.248 \\
\hline Actinobacillus & $2.71 \pm 1.45$ & $2.44 \pm 1.14$ & $0.96 \pm 0.29$ & $2.62 \pm 0.58$ & 0.261 \\
\hline Bacteroidetes (phylum) & $14.73 \pm 4.20$ & $19.60 \pm 4.03$ & $19.40 \pm 3.76$ & $15.24 \pm 4.13$ & 0.445 \\
\hline Alloprevotella & $2.33 \pm 1.18$ & $0.60 \pm 0.14$ & $1.90 \pm 0.91$ & $0.74 \pm 0.37$ & 0.163 \\
\hline Parabacteroides & $0.20 \pm 0.03$ & $0.80 \pm 0.48$ & $0.38 \pm 0.13$ & $0.35 \pm 0.18$ & 0.154 \\
\hline Unidentified Bacteroidales & $0.48 \pm 0.26$ & $0.26 \pm 0.16$ & $0.76 \pm 0.42$ & $0.09 \pm 0.03$ & 0.116 \\
\hline Actinobacteria (phylum) & $0.61 \pm 0.14$ & $0.70 \pm 0.14$ & $1.11 \pm 0.31$ & $0.56 \pm 0.02$ & 0.072 \\
\hline Bifidobacterium & $0.03 \pm 0.01^{a}$ & $0.04 \pm 0.02^{a}$ & $0.25 \pm 0.12^{b}$ & $0.04 \pm 0.01^{a}$ & 0.039 \\
\hline
\end{tabular}

$a, \bar{b}$ Different superscripts within a row indicate a significant difference $(p<0.05) .{ }^{1}$ Dietary treatments: CON $=$ basal diet; AGP = basal diet supplemented with $0.075 \mathrm{~g} / \mathrm{kg}$ chlortetracycline, $0.055 \mathrm{~g} / \mathrm{kg}$ kitasamycin, and $0.01 \mathrm{~g} / \mathrm{kg}$ virginiamycin; $\mathrm{CBN}=$ basal diet supplemented with $2.5 \times 10^{8} \mathrm{CFU} / \mathrm{kg} \mathrm{C}$. butyricum; $\mathrm{CBH}=$ basal diet supplemented with $2.5 \times 10^{9} \mathrm{CFU} / \mathrm{kg} \mathrm{C}$. butyricum. ${ }^{2} \mathrm{SE}$ : standard error of the mean. Each treatment group contains six replicates $(n=6)$, and each replicate includes one male piglet. 


\section{Discussion}

C. butyricum has been studied as a substitute for antibiotics in recent years, with most research concentrating on its effects on broilers. These studies have shown that $C$. butyricum can promote growth performance and improve nutrient utilization efficiency in broilers [24,25]. However, few studies indicated that $C$. butyricum did not affect growth performance in broilers and piglets [26,27]. Limited studies in piglets have shown that $C$. butyricum supplementation significantly decreased $F / G$ and average fecal score, having had no effects on those indices with the same strain and dose in another experiment [28]. A plausible reason for this observation might be associated with diet type, since C. butyricum with a relatively less digestible diet showed positive effects. The present study demonstrated that $C$. butyricum supplementation significantly increased feed efficiency and average fecal score in weaned piglets, which was as effective as AGPs. This is consistent with the previous findings, which showed that dietary C. butyricum increased growth performance and enhanced feed efficiency with a significant decrease of $\mathrm{F} / \mathrm{G}$ ratio, and diarrhea rate in weaned piglets $[5,29]$. Thus, it can be hypothesized that improved feed efficiency in piglets fed the C. butyricum diet might be related to greater nutrient ATTD and better intestinal health.

Contrary to research on other antibiotic alternatives, only a few studies have measured ATTD in piglets fed probiotics, especially for diets with C. butyricum. Previous studies have suggested that probiotic supplementation can improve digestibility of DM, CP, and crude fiber [30,31]. As expected, the present study suggested that supplementation with C. butyricum increased ATTD of DM, OM, and total carbohydrates compared to the CON group. This indicated that dietary C. butyricum increased the utilization efficiency of nutrients, which accounts for the enhanced feed efficiency of piglets. A probable mechanism by which C. butyricum increases ATTD may be associated with a healthy intestinal environment in response to increased digestive enzyme activity and large amounts of SCFAs [25]. A previous report indicated that administration of $C$. butyricum to Rex rabbits enhanced the digestive enzyme activity, including trypsin, $\alpha$-amylase, chymotrypsin, and cellulase activity to varying degrees [24]. Mounting evidence suggests that dietary supplementation with C. butyricum increases the concentrations of acetic acid, butyric acid, and total SCFAs in the intestinal digesta [11,26,29,32,33], which reduce gut $\mathrm{pH}$. These reports are basically consistent with the present study. A lower gut $\mathrm{pH}$ has been reported to contribute to nutrient digestibility due to their antibacterial effects on enterobacteria and increased secretion of digestive enzymes [34,35]. In addition, SCFAs benefit animals by providing energy for intestinal mucosal epithelial cells.

Intestinal morphology is commonly considered an important mechanical defense of barrier functions, where villus height and crypt depth are used for evaluating intestinal development and absorptive function [36]. A previous study has shown that dietary treatment with C. butyricum had a higher ileac villous height and lower crypt depth in broiler chickens [37] and broiler chickens challenged with E. coli K88 [38]. In a piglet study, piglets administered C. butyricum significantly increased jejunal villus height and ratio of the jejunal height to crypt depth [29]. The present study further demonstrated that dietary treatment with C. butyricum increased the intestinal villus height and crypt depth. The underlying mechanism was associated with metabolites of microbiota, especially butyric acid, which acts as a functional low molecular weight substance. Butyric acid was generally the main source of energy for epithelial cells and activated the mitotic activity of crypt enteric cells [39], potentially resulting in longer villi. Previous studies have demonstrated an increase in intestinal villus height after butyrate supplementation in weaning piglets $[35,40]$. Thus, these reports have indicated that $C$. butyricum metabolites may play an important role in improving gut health and increasing nutrient utilization. 
Serum Ig concentration can be used as a key parameter to reflect animal humoral immune status. Relatively high levels seem to be particularly necessary for weanling piglets because they are susceptible to stressors and pathogens [41]. In the present study, dietary treatment with C. butyricum significantly increased serum levels of IgA, IgM, and IgG compared to the CON diet. This was consistent with previous studies. Diet supplemented with C. butyricum has increased the level of serum IgM in piglets on day 14, and the level of serum IgG, IgA, and IgM in piglets on day 28 [29]. It has been reported that dietary supplementation with C. butyricum stimulated secretion of Igs in broilers [24,42], mice [43], and Peyer's patch cell [44]. Interestingly, SCFAs produced by C. butyricum can improve the immune function of mice by enhancing B cell antibody production [45]. These results demonstrated that $C$. butyricum plays a positive role in enhancing lymphocyte response and immune status, contributing to animal protection against pathogenic microorganisms. Cytokines, including IL- $1 \beta$, TNF- $\alpha$, and IL- 6 are key pro-inflammatory events that induce an inflammatory response in mammals. IL-1 $\beta$ usually increases the margination of lymphocytes by decreasing local blood flow rate, contributing to pathogen exclusion [46]. IL-6 acts on the mesenchymal cells to induce recruitment of macrophages and polymorphonuclear leukocytes to eliminate pathogens [47]. Previous report indicated that dietary supplementation with C. butyricum significantly decreased production of IL-1 $\beta$, IL-8, and TNF- $\alpha$ to a different extent in livers, spleens, and cecal tissues of chicken challenged with Salmonella enteritidis [48]. This effect was consistent with the present results. A similar result was found in a weaning Rex rabbit study where treatment with C. butyricum decreased the ileum levels of IL- 6 and TNF- $\alpha$ [49]. A potential mechanism responsible for this action might be associated with the Toll-like receptor (TLR)-mediated nuclear factor-kappa enhancer binding protein (NF- $\mathrm{KB}$ ) signaling pathway. C. butyricum can also mitigate inflammation in chickens after being challenged with Salmonella enteritidis by down-regulating the TLR4- and NF-kB-dependent pathway [48]. Furthermore, the present study indicated that a diet with C. butyricum significantly increased serum IL-2 level compared to the CON group. IL-2 is a pleiotropic cytokine that is required to prevent chronic inflammation and is necessary to maintain regulatory T cell secretion of IL-10 recognized as an anti-inflammatory cytokine $[47,50]$. These reports have demonstrated that $C$. butyricum might be a key modulator needed to maintain immunological host homeostasis.

Reactive oxygen species (ROS) have been associated with host defense, inflammation, and tissue damage [51]. Antioxidant enzymes participate in inactivation of ROS and degradation of superoxide anions and hydrogen peroxide [52]. In the current study, the CBN group significantly increased the inhibition ability of hydroxyl radical and GSH-PX activity and modestly decreased $\mathrm{H}_{2} \mathrm{O}_{2}$ serum concentration. This was in agreement with previous studies [24,49], which showed that diets with C. butyricum can increase the activity of GSH-PX, SOD, and CAT in intestine of broiler and Rex rabbits. In addition, C. butyricum's main metabolite butyric acid can modulate oxidative damage by reducing ROS and increasing the levels of antioxidative enzymes [53,54]. Improved immune function might partially contribute to enhance the antioxidant ability and suppress ROS production, because ROS are considered indispensable for host defense against an inflammatory threat [51]. ALT, AST, ALP, $\gamma$-GT, and CHE play an important role in liver function as main indicators. A previous study revealed that C. butyricum supplementation resulted in a considerable reduction in the serum ALT and AST activities in piglets [29]. In the mice model, C. butyricum also relieved acute liver damage induced by carbon tetrachloride [55]. Our results indicated that diet supplemented with C. butyricum decreased AST, ALP, $\gamma$-GT, and CHE activies, particularly in the CBN group.

The above positive effects of dietary C. butyricum may be mediated by improvements in microbiota composition. Phyla of Firmicutes and Bacteroidetes are the dominant members of colonic microbiota and most Bacteroide strains are amylolytic, hemicellulolytic, or proteolytic bacteria [56]. Bacteroides identified in the cecal samples contribute $31.9 \%$ of glycoside hydrolase genes, $26.1 \%$ of polysaccharide lyase genes, $20.7 \%$ of carbohydrate esterase genes, and $16.2 \%$ of glycosyltransferase genes [57]. In contrast, Proteobacteria are facultative anaerobic bacteria that do not specialize in fiber consumption and might even interfere with host nutrition by consuming fermentation products of carbon dioxide when oxygen 
is present [58]. The present study indicated that a modest increase in relative abundance of Bacteroidetes in the C. butyricum treatment might have been responsible for the depletion of Proteobacteria and Firmicute representatives. This was consistent with previous study [59]. Moreover, Bacteroides can hydrolyze indigestible dietary polysaccharides and supply 10-15\% of daily calories as fermentation products [60]. These might be some of the reasons that diets with C. butyricum had a lower F/G and higher ATTD compared to the CON group in the present study.

Actinobacteria are associated with maintenance of intestinal mucosal surface homeostasis and acetate production, in which Bifidobacterium as an obligate anaerobic bacteria is conducive to the development of immune system [61]. Sarcina is a genus of Gram-positive obligate anaerobic tetrad cluster cocci bacteria that have been frequently recovered from gastric samples of patients suffering from gastroparesis and peritonitis [62]. As a result of the present study, the CBN diet treatment significantly increased the relative abundance of Bifidobacterium compared to other treatments, while the relative abundance of Sarcina in the CBN, CBH, and AGP groups was modestly decreased. The present study indicated that supplementation with C. butyricum enriched the beneficial bacteria and decreased potential pathogens. Moreover, there seems to be a close correlation between microbiota and immunity or antioxidant resistance. It has been reported that Bifidobacterium can suppress pro-inflammatory cytokines by inhibiting NF- $\mathrm{B}$ B activation $[63,64]$. Correlation analysis showed that the relative abundance of Streptococcus and Roseburia was positively correlated with serum activity of T-AOC and GSH-PX and SCFAs concentrations in the intestine, while relative abundance of Blautia, Parabacteroides, and Marvinbryantia was negatively correlated with that of T-AOC, GSH-PX, and SCFAs [65]. This was consistent with the present results. Increased SCFAs levels resulting from dietary supplementation with $C$. butyricum in the present study might be associated with a significant increase in Streptococcus and Bifidobacterium and modest increase in Bacteroides and Anaerostipes. These can directly produce SCFAs, including acetic and butyric acids, or indirectly convert lactate to acetate via the methylmalonyl-CoA pathway, and finally utilize both acetate and lactate to synthesize butyrate via the butyryl-CoA:acetate-CoA-transferase route $[5,66]$. These results indicated that C. butyricum might shape a better metabolic milieu for the intestinal ecosystem by regulating microbiota and its metabolites of SCFAs, which benefit ATTD, antioxidant resistance, and immune function.

Compared to diet intervention and host genetics, weaning age might be an ignored factor that can generate collateral effects influencing gut development, and may result in microbial dysbiosis, subsequent diarrhea, and growth check [67]. Longitudinal studies of infants have demonstrated that adult-associated microbial community begin to dominate the infant microbiota post-weaning [68], indicating early weaning prematurely displaced beneficial infant-associated microbes, and then negative affected gut health [69]. With the development of livestock production, early weaning may become common, so that the weaning age of piglet decreased from 28 to 21 days old. Thus, the early weaning-associated problems obviously become prominent. Early colonization of beneficial microbe may be an effective way to positively impact animal gut and lifelong health. As reported, diet supplemented with $C$. butyricum reshaped microbial community structure, and enhanced the intestinal health and nutrient absorption in weaned piglets by improving intestinal histology [27,29]. Butyrate as the main metabolite of $C$. butyricum could directly provide energy for enterocytes to maintain the mucosal barrier [69]. Moreover, the microbial diversity significantly increased with the age of pig [70], indicating the piglet has a lower microbial diversity when suffering early weaning. Therefore, diet supplemented with C. butyricum may have a higher probability of C. butyricum colonization, and then contribute more to the gut and host health at 21 days weaning, compared to 28 days weaning. However, more research is needed to better evaluate the effects of $C$. butyricum in different weaning time. 


\section{Conclusions}

The study results suggest that dietary treatment with C. butyricum can increase the growth performance, decrease average fecal score, protect liver, and enhance health status in weaned piglets by improving serum immune function, antioxidant ability, and regulating the gut microbiota. C. butyricum could serve as a potential alternative to AGP administration in weanling piglets to promote growth and improve gut health. Moreover, it might present a better effect when applying in early weaning or even pre-weaning.

Author Contributions: Conceptualization, Y.H. and Q.Z.; methodology, Y.H. and Y.L.; data curation, Y.H.; software, Y.H. and C.T.; formal analysis, Y.H.; investigation, Y.H. and T.Z.; resources, Y.H. and Y.L.; writing-original draft, Y.H.; writing-review and editing, C.T. and J.Z.; supervision, Y.Y. and Q.Z.; project administration, J.Z. and Q.Z.; funding acquisition, J.Z. All authors have read and agreed to the published version of the manuscript.

Funding: This work was supported by the National Innovation Program of Agricultural Science and Technology in the Chinese Academy of Agricultural Sciences, Key Project of Alternatives to Antibiotic for Feed Usages (No. CAAS-ZDXT2018008), and the Agricultural Science and Technology Innovation Program (ASTIP-IAS12).

Acknowledgments: We thank students in the functional livestock products team of Institute of Animal Science of Chinese Academy of Agricultural Sciences for their technical assistance. We thank the Academy of Baolai-Leelai Biology Technology and Inner Mongolia Xingdaye Agriculture and Animal Husbandry Company Limited for their assistance with the animal experiment.

Conflicts of Interest: The authors declare no conflict of interest. The authors declare no competing financial interests. The funders had no role in the design of the study; in the collection, analyses, or interpretation of data; in the writing of the manuscript, or in the decision to publish the results.

\section{References}

1. Campbell, J.M.; Crenshaw, J.D.; Polo, J. The biological stress of early weaned piglets. J. Anim. Sci. Biotechnol. 2013, 4, 19. [CrossRef] [PubMed]

2. Xun, W.; Shi, L.; Zhou, H.; Hou, G.; Cao, T.; Zhao, C. Effects of curcumin on growth performance, jejunal mucosal membrane integrity, morphology and immune status in weaned piglets challenged with enterotoxigenic escherichia coli. Int. Immunopharmacol. 2015, 27, 46-52. [CrossRef] [PubMed]

3. Verstegen, M.W.; Williams, B.A. Alternatives to the use of antibiotics as growth promoters for monogastric animals. Anim. Biotechnol. 2002, 13, 113-127. [CrossRef] [PubMed]

4. Zimmermann, B.; Bauer, E.; Mosenthin, R. Pro-and prebiotics in pig nutrition-potential modulators of gut health? J. Anim. Feed Sci. 2001, 10, 47-56. [CrossRef]

5. Zhang, J.; Chen, X.; Liu, P.; Zhao, J.; Sun, J.; Guan, W.; Johnston, L.J.; Levesque, C.L.; Fan, P.; He, T. Dietary clostridium butyricum induces a phased shift in fecal microbiota structure and increases the acetic acid-producing bacteria in a weaned piglet model. J. Agric. Food Chem. 2018, 66, 5157-5166. [CrossRef]

6. Kong, Q.; He, G.Q.; Jia, J.L.; Zhu, Q.L.; Hui, R. Oral administration of clostridium butyricum for modulating gastrointestinal microflora in mice. Curr. Microbiol. 2011, 62, 512. [CrossRef]

7. Motomichi, T.; Haruhiko, T.; Hiroyuki, Y.; Takako, O.; Akio, K.; Shigeru, K. The effect of probiotic treatment with clostridium butyricum on enterohemorrhagic escherichia coli o157:H7 infection in mice. FEMS Immunol. Med. Mic. 2004, 41, 219-226.

8. Woo, T.D.H.; Oka, K.; Takahashi, M.; Hojo, F.; Osaki, T.; Hanawa, T.; Kurata, S.; Yonezawa, H.; Kamiya, S. Inhibition of the cytotoxic effect of clostridium difficile in vitro by clostridium butyricum miyairi 588 strain. J. Med. Microbiol. 2011, 60, 1617-1625. [CrossRef]

9. Seki, H.; Shiohara, M.; Matsumura, T.; Miyagawa, N.; Tanaka, M.; Komiyama, A.; Kurata, S. Prevention of antibiotic-associated diarrhea in children by clostridium butyricum miyairi. Pediatr. Int. 2010, 45, 86-90. [CrossRef]

10. Chang, H.; Peixia, S.; Peixin, F.; Chengli, H.; Phil, T.; Xi, M. Dietary sodium butyrate decreases postweaning diarrhea by modulating intestinal permeability and changing the bacterial communities in weaned piglets. J. Nutr. 2015, 145, 2774-2780.

11. Cassir, N.; Benamar, S.; Scola, B.L. Clostridium butyricum: From beneficial to a new emerging pathogen. Clin. Microbiol. Infect. 2016, 22, 37-45. [CrossRef] [PubMed] 
12. MacArthur Clark, J.A.; Sun, D. Guidelines for the ethical review of laboratory animal welfare People's Republic of China national standard gb/t 35892-2018 [issued 6 February 2018 effective from 1 September 2018]. Anim. Model Exp. Med. 2020, 3, 103-113. [CrossRef] [PubMed]

13. National Research Council. Nutrient Requirements of Swine, 11th ed.; National Academy Press: Washington, DC, USA, 2012.

14. EFSA. Scientific opinion on miya-gold ${ }^{\circledR}$ (clostridium butyricum) as a feed additive for weaned piglets, minor weaned porcine species and minor avian species. EFSA J. 2011, 9, 1951. [CrossRef]

15. O'Shea, C.J.; Mcalpine, P.; Sweeney, T.; Varley, P.F.; O'Doherty, J.V. Effect of the interaction of seaweed extracts containing laminarin and fucoidan with zinc oxide on the growth performance, digestibility and faecal characteristics of growing piglets. Br. J. Nutr. 2014, 111, 798-807. [CrossRef] [PubMed]

16. AOAC. Official Methods of Analysis, 19th ed.; Association of Official Analytical Chemists: Arlington, VA, USA, 2012.

17. Williams, C.H.; David, D.J.; Iismaa, O. The determination of chromic oxide in faeces samples by atomic spectrophotometry. J. Argic. Sci. 1962, 59, 381-385. [CrossRef]

18. Gerritsen, R.; Dijk, A.J.V.; Rethy, K.; Bikker, P. The effect of blends of organic acids on apparent faecal digestibility in piglets. Livest. Sci. 2010, 134, 246-248. [CrossRef]

19. Li, Z.; Weida, W.; Yuan-Kun, L.; Jingjing, X.; Hongfu, Z. Spatial heterogeneity and co-occurrence of mucosal and luminal microbiome across swine intestinal tract. Front. Microbiol. 2018, 9, 48.

20. So, D.; Yao, C.; Gill, P.; Pillai, N.; Gibson, P.; Muir, J. In Vitro screening dietary fibres for fermentation characteristics and metabolic profiles using a rapid approach: Implications for irritable bowel syndrome. Br. J. Nutr. 2020, 1-11. [CrossRef]

21. Hopwood, D.E.; Pethick, D.W.; Pluske, J.R.; Hampson, D.J. Addition of pearl barley to a rice-based diet for newly weaned piglets increases the viscosity of the intestinal contents, reduces starch digestibility and exacerbates post-weaning colibacillosis. Br. J. Nutr. 2004, 92, 419-427. [CrossRef]

22. Han, Y.; Zhan, T.; Zhao, Q.; Tang, C.; Zhang, K.; Han, Y.; Zhang, J. Effects of mixed organic acids and medium chain fatty acids as antibiotic alternatives on the performance, serum immunity, and intestinal health of weaned piglets orally challenged with escherichia coli k88. Anim. Feed Sci. Technol. 2020, 269, 114617. [CrossRef]

23. Xu, Z.; Hu, C.; Xia, M.; Zhan, X.; Wang, M. Effects of dietary fructooligosaccharide on digestive enzyme activities, intestinal microflora and morphology of male broilers. Poult. Sci. 2003, 82, 1030-1036. [CrossRef] [PubMed]

24. Liao, X.D.; Ma, G.; Cai, J.; Fu, Y.; Yan, X.Y.; Wei, X.B.; Zhang, R.J. Effects of clostridium butyricum on growth performance, antioxidation, and immune function of broilers. Poult. Sci. 2015, 94, 662-667. [CrossRef] [PubMed]

25. Zhao, X.; Guo, Y.; Guo, S.; Tan, J. Effects of clostridium butyricum and enterococcus faecium on growth performance, lipid metabolism, and cecal microbiota of broiler chickens. Appl. Microbiol. Biotechnol. 2013, 97, 6477-6488. [CrossRef] [PubMed]

26. Zhang, B.; Xin, Y.; Guo, Y.; Long, F. Effects of dietary lipids and clostridium butyricum on the performance and the digestive tract of broiler chickens. Arch. Anim. Nutr. 2011, 65, 329-339. [CrossRef] [PubMed]

27. Sato, Y.; Kuroki, Y.; Oka, K.; Takahashi, M.; Rao, S.; Sukegawa, S.; Fujimura, T. Effects of dietary supplementation with enterococcus faecium and clostridium butyricum, either alone or in combination, on growth and fecal microbiota composition of post-weaning pigs at a commercial farm. Front. Vet. Sci. 2019, 6, 26. [CrossRef] [PubMed]

28. Chen, L.; Li, S.; Zheng, J.; Li, W.; Jiang, X.; Zhao, X.; Li, J.; Che, L.; Lin, Y.; Xu, S. Effects of dietary clostridium butyricum supplementation on growth performance, intestinal development, and immune response of weaned piglets challenged with lipopolysaccharide. J. Anim. Sci. Biotechnol. 2018, 9, 62. [CrossRef] [PubMed]

29. Wang, K.; Cao, G.; Zhang, H.; Li, Q. Effects of clostridium butyricum and enterococcus faecalis on growth performance, immune function, intestinal morphology, volatile fatty acids, and intestinal flora in a piglet model. Food Funct. 2019, 10, 7844-7854. [CrossRef]

30. Giang, H.H.; Viet, T.Q.; Ogle, B.; Lindberg, J.E. Growth performance, digestibility, gut environment and health status in weaned piglets fed a diet supplemented with potentially probiotic complexes of lactic acid bacteria. Livest. Sci. 2010, 129, 95-103. [CrossRef] 
31. Giang, H.H.; Viet, T.Q.; Ogle, B.; Lindberg, J.E. Effects of supplementation of probiotics on the performance, nutrient digestibility and faecal microflora in growing-finishing pigs. Asian-Australas J. Anim. 2011, 24, 655-661. [CrossRef]

32. Han, J.; Wang, Y.; Dan, S.; Lu, Z.; Dong, Z.; Miao, H.; Wang, W.; He, J.; Li, A. Effects of clostridium butyricum and lactobacillus plantarum on growth performance, immune function and volatile fatty acid level of caecal digesta in broilers. Food Agric. Immunol. 2018, 29, 797-807. [CrossRef]

33. Araki, Y.; Andoh, A.; Fujiyama, Y.; Takizawa, J.; Takizawa, W.; Bamba, T. Oral administration of a product derived from clostridium butyricum in rats. Int. J. Mol. Med. 2002, 9, 53. [CrossRef] [PubMed]

34. Lyberg, K.; Lundh, T.; Pedersen, C.; Lindberg, J.E. Influence of soaking, fermentation and phytase supplementation on nutrient digestibility in pigs offered a grower diet based on wheat and barley. Anim. Sci. 2006, 82, 853-858. [CrossRef]

35. Long, S.F.; Xu, Y.T.; Pan, L.; Wang, Q.Q.; Wang, C.L.; Wu, J.Y.; Wu, Y.Y.; Han, Y.M.; Yun, C.H.; Piao, X.S. Mixed organic acids as antibiotic substitutes improve performance, serum immunity, intestinal morphology and microbiota for weaned piglets. Anim. Feed Sci. Technol. 2017, 235, 23-32. [CrossRef]

36. Montagne, L.; Cavaney, F.; Hampson, D.; Lallès, J.; Pluske, J. Effect of diet composition on postweaning colibacillosis in piglets. J. Anim. Sci. 2004, 82, 2364-2374. [CrossRef] [PubMed]

37. Lee, K.W.; Lee, S.H.; Lillehoj, H.S.; Li, G.X.; Jang, S.I.; Babu, U.S.; Park, M.S.; Kim, D.K.; Lillehoj, E.P.; Neumann, A.P. Effects of direct-fed microbials on growth performance, gut morphometry, and immune characteristics in broiler chickens. Poult. Sci. 2010, 89, 203-216. [CrossRef] [PubMed]

38. Zhang, L.; Zhang, L.; Zhan, X.; Zeng, X.; Zhou, L.; Cao, G. Effects of dietary supplementation of probiotic, clostridium butyricum, on growth performance, immune response, intestinal barrier function, and digestive enzyme activity in broiler chickens challenged with escherichia coli k88. J. Anim. Husb. Biotechnol. 2016, 7, 107-115. [CrossRef]

39. Partanen, K.H.; Mroz, Z. Organic acids for performance enhancement in pig diets. Nutr. Res. Rev. 1999, 12, 117-145. [CrossRef] [PubMed]

40. Wang, J.F.; Chen, Y.X.; Wang, Z.X.; Dong, S.H.; Lai, Z.W. Effect of sodium butyrate on structure of small intestine mucous epithelium in weaning piglets. Chin. J. Vet. Sci. 2005, 4, 298-301.

41. Yoon, J.H.; Ingale, S.L.; Kim, J.S.; Kim, K.H.; Lee, S.H.; Park, Y.K.; Kwon, I.K.; Chae, B.J. Effects of dietary supplementation of antimicrobial peptide-a3 on growth performance, nutrient digestibility, intestinal and fecal microflora and intestinal morphology in weanling pigs. Anim. Feed Sci. Technol. 2012, 177, 98-107. [CrossRef]

42. Yang, C.M.; Cao, G.T.; Ferket, P.R.; Liu, T.T.; Zhou, L.; Zhang, L.; Xiao, Y.P.; Chen, A.G. Effects of probiotic, clostridium butyricum, on growth performance, immune function, and cecal microflora in broiler chickens. Poult. Sci. 2012, 91, 2121-2129. [CrossRef]

43. Wang, G.R.; Chen, H.Y.; Chen, C.H.; Yeh, M.Y.; Mikami, Y. Immunopotentiating activity of clostridium butyricum in mice. Proc. Natl. Acad. Sci. USA 1996, 20, 101.

44. Murayama, T.I.; Mita, N.; Tanaka, M.; Kitajo, T.; Asano, T.; Mizuochi, K.; Kaneko, K.I. Effects of orally administered clostridium butyricum miyairi 588 on mucosal immunity in mice. Vet. Immunol. Immunop. 1995, 48, 333-342. [CrossRef]

45. Wenjing, Y.; Yi, X.; Xiangsheng, H.; Feidi, C.; Mingming, S.; Bilotta, A.J.; Leiqi, X.; Yao, L.; Suxia, Y.; Qihong, Z. Microbiota metabolite short-chain fatty acids facilitate mucosal adjuvant activity of cholera toxin through gpr43. J. Immunol. 2020, 203, 282-292.

46. Schroder, K. Interferon-gamma: An overview of signals, mechanisms and functions. J. Leukoc. Biol. 2004, 75, 163-189. [CrossRef] [PubMed]

47. Friedrich, M.; Pohin, M.; Powrie, F. Cytokine networks in the pathophysiology of inflammatory bowel disease. Immunity 2019, 50, 992-1006. [CrossRef]

48. Zhao, X.; Jie, Y.; Wang, L.; Hai, L.; Sun, S. Protection mechanism of clostridium butyricum against salmonella enteritidis infection in broilers. Front. Microbiol. 2017, 8, 1523. [CrossRef]

49. Liu, L.; Zeng, D.; Yang, M.; Wen, B.; Lai, J.; Zhou, Y.; Sun, H.; Xiong, L.; Wang, J.; Lin, Y. Probiotic clostridium butyricum improves the growth performance, immune function, and gut microbiota of weaning rex rabbits. Probiotics Antimicrob. Proteins 2019, 11, 1278-1292. [CrossRef] 
50. Sun, M.; Wu, W.; Chen, L.; Yang, W.; Huang, X.; Ma, C.; Chen, F.; Xiao, Y.; Zhao, Y.; Ma, C.; et al. Microbiota-derived short-chain fatty acids promote Th1 cell IL-10 production to maintain intestinal homeostasis. Nat. Commun. 2018, 9, 3555. [CrossRef]

51. Aviello, G.; Knaus, U.G. Nadph oxidases and ros signaling in the gastrointestinal tract. Mucosal Immunol. 2018, 11, 1011-1023. [CrossRef]

52. Shen, X.; Yi, D.; Ni, X.; Zeng, D.; Jing, B.; Lei, M.; Bian, Z.; Zeng, Y.; Li, T.; Xin, J. Effects of lactobacillus plantarum on production performance, immune characteristics, antioxidant status, and intestinal microflora of bursin-immunized broilers. Can. J. Microbiol. 2014, 60, 193-202. [CrossRef]

53. Hamer, H.; Jonkers, D.; Aalt, B.; Vanhoutvin, S.; Fischer, M.; Andrea, K.; Troost, F.; Koen, V.; Brummer, R.J. Butyrate modulates oxidative stress in the colonic mucosa of healthy humans. Clin. Nutr. 2009, 28, 88-93. [CrossRef] [PubMed]

54. Jahns, F.; Jahns, A.; Jablonowski, N.; Mothes, H.; Greulich, K.O.; Glei, M. Butyrate modulates antioxidant enzyme expression in malignant and non-malignant human colon tissues. Mol. Carcinogen. 2015, 54, $249-260$. [CrossRef] [PubMed]

55. Liu, J.; Fu, Y.; Zhang, H.; Wang, J.; Wang, F. The hepatoprotective effect of the probiotic clostridium butyricum against carbon tetrachloride-induced acute liver damage in mice. Food Funct. 2017, 8, 4042-4052. [CrossRef] [PubMed]

56. Li, R.; Hou, G.; Jiang, X.; Song, Z.; Fan, Z.; Hou, D.X.; He, X. Different dietary protein sources in low protein diets regulate colonic microbiota and barrier function in a piglet model. Food Funct. 2019, 10, 6417-6428. [CrossRef]

57. Xia, Y.; Kong, J.; Zhang, G.; Zhang, X.; Seviour, R.; Kong, Y. Effects of dietary supplementation with lysozyme on the structure and function of the cecal microbiota in broiler chickens. PLoS ONE 2019, 14, e0216748. [CrossRef]

58. Litvak, Y.; Byndloss, M.X.; Bäumler, A.J. Colonocyte metabolism shapes the gut microbiota. Science 2018, 362, 1017. [CrossRef]

59. Cao, M.; Li, Y.; Wu, Q.; Zhang, P.; Li, W.; Mao, Z.; Wu, D.; Jiang, X.; Zhuo, Y.; Fang, Z.; et al. Effects of dietary clostridium butyricum addition to sows in late gestation and lactation on reproductive performance and intestinal microbiota1. J. Anim. Sci. 2019, 97, 3426-3439. [CrossRef]

60. Xu, J.; Bjursell, M.K.; Himrod, J.; Deng, S.; Carmichael, L.K.; Chiang, H.C.; Hooper, L.V.; Gordon, J.I. A genomic view of the human-bacteroides thetaiotaomicron symbiosis. Science 2003, 299, 2074-2076. [CrossRef]

61. Herfel, T.M.; Jacobi, S.K.; Lin, X.; Jouni, Z.E.; Chichlowski, M.; Stahl, C.H.; Odle, J. Dietary supplementation of bifidobacterium longum strain ah1206 increases its cecal abundance and elevates intestinal interleukin-10 expression in the neonatal piglet. Food Chem. Toxicol. 2013, 60, 116-122. [CrossRef]

62. Bortolotti, P.; Kipnis, E.; Faure, E.; Faure, K.; Wacrenier, A.; Fauquembergue, M.; Penven, M.; Messaadi, D.; Marceau, L.; Dessein, R.; et al. Clostridium ventriculi bacteremia following acute colonic pseudo-obstruction: A case report. Anaerobe 2019, 59, 32-34. [CrossRef]

63. Elise, H.; Corinne, L.; Maurice, B.; Nadine, C.B.; Martine, H. A bifidobacterium probiotic strain and its soluble factors alleviate chloride secretion by human intestinal epithelial cells. J. Nutr. 2010, 140, 7-11.

64. Kim, S.W.; Hee Man, K.; Kyoung Min, Y.; Sun-Ah, K.; Sung-Kyu, K.; Ji, A.M.; Jae Jun, P.; Kil, L.S.; Won Ho, K. Bifidobacterium lactis inhibits nf-kappab in intestinal epithelial cells and prevents acute colitis and colitis-associated colon cancer in mice. Inflamm. Bowel Dis. 2010, 16, 1514-1525. [CrossRef] [PubMed]

65. Wang, Y.; Xie, Q.; Sun, S.; Huang, B.; Zhang, Y.; Xu, Y.; Zhang, S.; Xiang, H. Probiotics-fermented massa medicata fermentata ameliorates weaning stress in piglets related to improving intestinal homeostasis. Appl. Microbiol. Biot. 2018, 102, 10713-10727. [CrossRef] [PubMed]

66. Koh, A.; De, V.F.; Kovatchevadatchary, P.; Bäckhed, F. From dietary fiber to host physiology: Short-chain fatty acids as key bacterial metabolites. Cell 2016, 165, 1332-1345. [CrossRef]

67. Zhuang, Y.; Chai, J.; Cui, K.; Bi, Y.; Zhang, N. Longitudinal investigation of the gut microbiota in goat kids from birth to postweaning. Microorganisms 2020, 8, 1111. [CrossRef]

68. Bergström, A.; Skov, T.; Bahl, M.; Roager, H.; Christensen, L.; Ejlerskov, K.; Mølgaard, C.; Michaelsen, K.; Licht, T. Establishment of intestinal microbiota during early life: A longitudinal, explorative study of a large cohort of danish infants. Appl. Environ. Microb. 2014, 80, 2889-2900. [CrossRef] 
69. Differding, M.; Benjamin-Neelon, S.; Hoyo, C.; Østbye, T.; Mueller, N. Timing of complementary feeding is associated with gut microbiota diversity and composition and short chain fatty acid concentrations over the first year of life. BMC Microbiol. 2020, 20, 56. [CrossRef]

70. Ke, S.; Fang, S.; He, M.; Huang, X.; Huang, L. Age-based dynamic changes of phylogenetic composition and interaction networks of health pig gut microbiome feeding in a uniformed condition. BMC Vet. Res. 2019, 15, 1-13. [CrossRef]

Publisher's Note: MDPI stays neutral with regard to jurisdictional claims in published maps and institutional affiliations.

(C) 2020 by the authors. Licensee MDPI, Basel, Switzerland. This article is an open access article distributed under the terms and conditions of the Creative Commons Attribution (CC BY) license (http://creativecommons.org/licenses/by/4.0/). 